\title{
Ectopic Induction of Tendon and Ligament in Rats by Growth and Differentiation Factors 5, 6, and 7, Members of the TGF- $\beta$ Gene Family
}

\author{
Neil M. Wolfman, Gary Hattersley, Karen Cox, Anthony J. Celeste, Robin Nelson, Noboru Yamaji, Jennifer L. Dube, \\ Elizabeth DiBlasio-Smith, John Nove, Jeffrey J. Song, John M. Wozney, and Vicki Rosen \\ Genetics Institute, Inc., Cambridge, Massachusetts 02140
}

\begin{abstract}
Little is known about the regulatory signals involved in tendon and ligament formation, and this lack of understanding has hindered attempts to develop biologically based therapies for tendon and ligament repair. Here we report that growth and differentiation factors (GDFs) 5, 6, and 7, members of the TGF- $\beta$ gene superfamily that are most related to the bone morphogenetic proteins, induce neotendon/ligament formation when implanted at ectopic sites in vivo. Analysis of tissue induced by GDF-5, 6, or 7, containing implants by currently available morphological and molecular criteria used to characterize tendon and ligament, adds further evidence to the idea that these GDFs act as signaling molecules during embryonic tendon/ligament formation. In addition, comparative in situ localizations of the GDF-5, 6, and $7 \mathrm{mRNAs}$ suggest that these molecules are important regulatory components of synovial joint morphogenesis. $(J$. Clin. Invest. 1997. 100:321-330.) Key words: tendon • ligament $\bullet$ bone morphogenic proteins - tissue repair $\bullet$ orthopedics
\end{abstract}

\section{Introduction}

Tendons are the tough yet flexible connective tissue straps that physically bind muscles to skeletal structures. Composed of bundles of collagen that are held together by a layer of loose connective tissue, they are well-suited for their role as transducers, enabling the force of a muscle to be exerted at a distance from the muscle itself. Ligaments, which are very similar structurally to tendons, but appear to have more elastic fibers, attach adjacent bones to one another and maintain them at their correct anatomical positions during movement. They also provide structural support around joint capsules, and at sites where bones make contact with other bones (1-3).

Neil M. Wolfman, Gary Hattersley, Karen Cox, and Anthony J. Celeste made equal contributions to this manuscript.

Address correspondence to Vicki Rosen, Ph.D., Genetics Institute, 87 CambridgePark Drive, Cambridge, MA 02140. Phone: 617498-8365; FAX: 617-498-8875; E-mail: vrosen@genetics.com The current address of Robin Nelson is Pfizer Central Research, Groton, Connecticut. The current address of Noburu Yamaji is Yamanouchi Pharmaceutical Co. Ltd., Tsukuba-City, Japan.

Received for publication 22 October 1996 and accepted in revised form 18 April 1997.

J. Clin. Invest.

(C) The American Society for Clinical Investigation, Inc.

0021-9738/97/07/0321/10 \$2.00

Volume 100, Number 2, July 1997, 321-330
Little is known about the organogenesis of tendons and ligaments. Both structures appear as mesenchymal condensations starting in the mouse at day 14 postconception $\left(\mathrm{dpc}^{1} 14\right)$. These rudiments lie adjacent to the newly formed cartilages that become the bones of the skeleton. As tendons and ligaments develop, they insert into the surfaces of adjacent bones using an as of yet uncharacterized positional information process (4). There appears to be a transition in cell phenotype at each insertion site so that when examined morphologically, a continuum of differentiation stages of connective tissue cells (fibrocartilage cell to tendon/ligament cell) is present $(5,6)$. The recent identification of novel homeobox-containing genes expressed in embryonic tendons suggests that the patterning mechanisms important for controlling skeletal development are likely to affect tendon and ligament formation as well (7-9).

Isolation of the cell populations that differentiate to form tendons and ligaments has been hindered by the lack of specific markers that define these tissues. For example, the primary components of tendons and ligaments are collagen type I, elastin, and decorin, structural proteins found in the extracellular matrix (ECM) of most connective tissues. The cell types resident in tendons/ligaments are responsive to a variety of growth factors, including members of the TGF- $\beta$ gene family $(10,11,12)$. Understanding these and other yet-to-be identified signals may be useful in designing new treatments for tendon and ligament injuries that under current medical practice show poor long-term clinical outcomes. Treatment for rupture of the anterior cruciate ligament, the most common knee injury in humans, typically involves replacement of the anterior cruciate ligament with a tendon autograft from another anatomic site. While providing limited return of function in most cases, these grafts eventually die and are replaced by fibrous scar tissue that ultimately leads to permanent instability of the knee, impairment of joint function, and increased likelihood of osteoarthritis (13-16).

We recently identified and expressed the human equivalents of the murine growth and differentiation factors (GDF)s 5, 6, and 7 (Fig. 1; 17, 18). These three molecules form a distinct subgroup within the TGF- $\beta /$ bone morphogenetic protein (BMP) gene family. In light of reports by Storm et al. (19) suggesting the absence of GDF-5 as the cause of the skeletal abnormalities seen in the $b p / b p$ (brachypod) mouse phenotype, and by Chang et al. (20) localizing GDF-5 and GDF-6 transcripts to developing cartilage, we expected that these molecules would be osteogenic proteins, and would induce endochondral bone formation when tested in the rat ectopic bone

1. Abbreviations used in this paper: BMP, bone morphogenetic protein; DBM, demineralized bone matrix; dpc, days postconception; ECM, extracellular matrix; EM, electron microscopy; GDF, growth and differentiation factor; LM, light microscopy. 
formation assay (21). Instead, we found that the human equivalents of GDFs 5, 6, and 7 all induced the formation of a connective tissue rich in collagen type I fibers which, when studied histologically, displayed a wave form and regular periodicity resembling embryonic or neonatal tendon and ligament. This observation lead us to characterize extensively the GDFinduced tissues, and to conclude that by all criteria currently available, these tissues can be considered neotendon/ligament.

\section{Methods}

\section{Cloning of human GDFs 5, 6, and 7}

Degenerate oligonucleotides designed on the basis of regions of high amino acid conservation between members of the BMP family were used to generate BMP-related sequences from a human genomic template using PCR. The sequences of the oligonucleotides used in the degenerate PCR experiments and the corresponding consensus amino acid sequences from which they are derived are as follows: CGGATCCTGVANGAYTGGATHRTNGC (Trp-Gln/Asn-Asp-TrpIle-Val/Ile-Ala) and TTTCTAGAARNGTYTGNACDATNGCRTG (His-Ala-Ile-Val/Leu-Gln-Thr-Leu). The underlined regions of these oligonucleotides represent the recognition sequences for the restriction endonucleases BamHI and XbaI, respectively, and have been included to facilitate the subcloning of BMP-related PCR products generated by this approach. Human genomic DNA sheared by repeated passage through a 25 -gauge needle, denatured at $100^{\circ} \mathrm{C}$ for $5 \mathrm{~min}$, and then chilled on ice was added to a reaction mixture containing 200 $\mu \mathrm{M}$ of each deoxynucleotide triphosphate (dATP, dGTP, dCTP, and dTTP), $10 \mathrm{mM}$ Tris-HCl, pH 8.3, $50 \mathrm{mM} \mathrm{KCl}, 1.5 \mathrm{mM} \mathrm{MgCl}_{2}, 0.001 \%$ gelatin, $1.25 \mathrm{U}$ Taq DNA polymerase, and $100 \mathrm{pM}$ each of the two degenerate oligonucleotides. The reaction mixture was incubated at $94^{\circ} \mathrm{C}$ for $2 \mathrm{~min}$, and was then subjected to thermal cycling: $1 \mathrm{~min}$ at $94^{\circ} \mathrm{C}, 1 \mathrm{~min}$ at $40^{\circ} \mathrm{C}, 1 \mathrm{~min}$ at $72^{\circ} \mathrm{C}$ for three cycles; $1 \mathrm{~min}$ at $94^{\circ} \mathrm{C}, 1 \mathrm{~min}$ at $55^{\circ} \mathrm{C}, 1 \mathrm{~min}$ at $72^{\circ} \mathrm{C}$ for 37 cycles, followed by a 10 - min incubation at $72^{\circ} \mathrm{C}$. The 128 -bp DNA products generated by this procedure were subcloned into pGEM-3, and were examined by DNA sequence analysis for the presence of BMP-related sequences. The sequence derived from one of the subclones was used to design an oligonucleotide probe (CCACTGCAGGCCTTTGCGACTTCCCTTTGCGTTCGCAC), which was used in screening a human genomic library constructed in the vector $\lambda$ FIX (No. 944201; Stratagene Inc., La Jolla, CA). A single positive recombinant $\lambda \mathrm{HuG}-48$ was identified, and the oligonucleotide-hybridizing region was subcloned into pGEM-3. The partial amino acid sequence of the human GDF-7 gene shown was derived from this insert. A DNA fragment that encodes amino acids 31-129 of the partial hGDF-7 sequence was hybridized to a human genomic library under reduced stringency conditions $(5 \times \mathrm{SSC} / 5 \times$ Denhardt's solution $/ 0.1 \%$ SDS $/ 100 \mu \mathrm{g}$ denatured salmon sperm DNA at $60^{\circ} \mathrm{C}$; wash $=2 \times \mathrm{SSC} / 0.1 \%$ SDS at $60^{\circ} \mathrm{C}$ ) resulting in the identification of hGDF-7-related genes. DNA sequence analysis of one of the positively hybridizing genomic clones defines the partial sequence of hGDF-6. This sequence was used to derive the amino acid sequence of hGDF-6 shown here.

A DNA fragment that encodes amino acids 36-130 of the hGDF-7 sequence was used to screen a mouse genomic library (946308; Stratagene Inc.) under reduced stringency $(5 \times \mathrm{SSC} / 5 \times$ Denhardt's solution $/ 0.1 \% \mathrm{SDS} / 100 \mu \mathrm{g}$ denatured salmon sperm DNA at $60^{\circ} \mathrm{C}$; wash $1 \times \mathrm{SSC} / 0.1 \% \mathrm{SDS}$ at $60^{\circ} \mathrm{C}$ ) to identify clones corresponding to murine GDF-5, 6, and 7. Probes for in situ localization studies consisted of a 538-bp fragment of mGDF-5 propeptide-encoding sequence, a 390 -bp fragment of mGDF-6 propeptide-encoding sequence, and a 462-bp fragment of mGDF-7 3' untranslated sequence.

\section{Rat ectopic assay}

Demineralized rat bone matrix particles (DBM) were used as a carrier matrix for GDFs and BMPs. Midshaft regions of rat femurs were cleaned of all bone marrow components, defatted in absolute ethanol followed by ether, air-dried, frozen, pulverized in liquid nitrogen, and sieved to obtain bone particles of 75-250 $\mu \mathrm{m}$. Bone particles were then extracted with $0.6 \mathrm{M} \mathrm{HCl}$ to remove any remaining bone mineral, and with $4.0 \mathrm{M}$ guanidine $\mathrm{HCl}$ to remove any remaining growth factors, producing an inert carrier matrix.

A

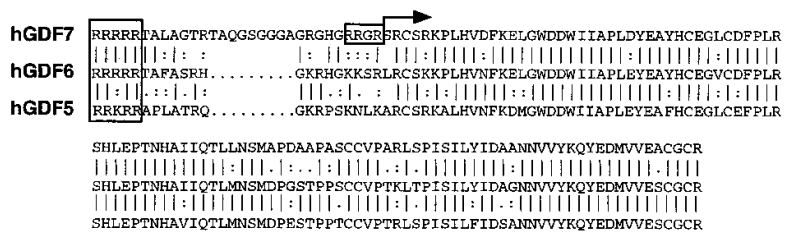

B

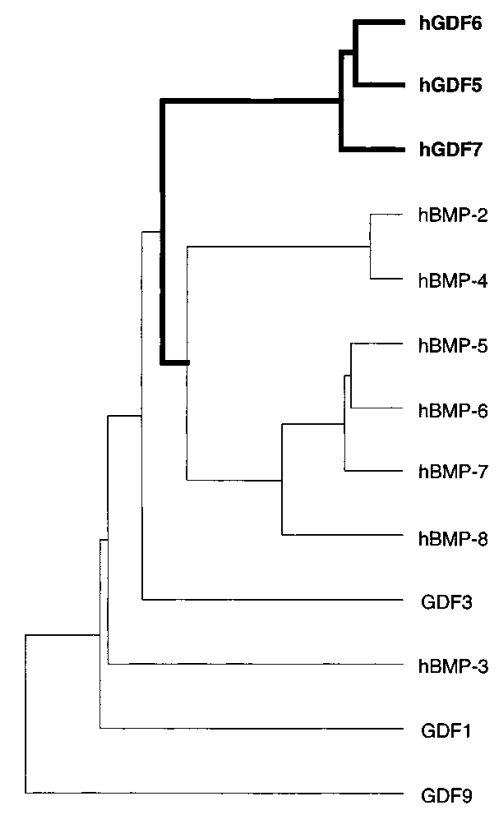

Figure 1. Sequences of human GDF-5 (GenBank Accession, No. X80915; 17), GDF-6, and GDF-7 and their relationship to other members of the BMP/GDF gene family. ( $A$ ) Partial amino acid sequence of human GDF-6 and GDF-7 are deduced from genomic clones. Amino acid identity between murine and human GDFs is 97\% for GDF-5, 99\% for GDF-6, and 97\% for GDF-7. Consensus proteolytic processing site, Arg-X-X-Arg, (boxed and shaded) predicts mature GDF-5 and GDF-6 peptides of 120 amino acids each, while the mature GDF-7 peptide anticipated by proteolytic cleavage at this site would be 129 amino acids. An alternative processing site, defined by the sequence Arg-Arg-Gly-Arg (boxed) present in hGDF-7 could result in a mature peptide containing an $\mathrm{NH}_{2}$-terminal extension of only two amino acids preceding the first conserved cysteine residue (the amino terminus of this alternative mature peptide is indicated with a rightward arrow). The potential proteolytic processing site that is conserved between hGDF- 6 and hGDF-7 creates a longer $\mathrm{NH}_{2}$-terminal extension of the hGDF-7 mature region, more consistent with that reported for BMPs (18). Both forms of rhGDF-7 (the shorter 104-amino acid form with the $\mathrm{NH}_{2}$-terminal sequence of Ser-Arg-Cys, and the 129-amino acid form with the $\mathrm{NH}_{2}$-terminal sequence Thr-Ala-Leu) have been expressed in Escherichia coli and refolded to form biologically active homodimers that can induce formation of neotendon/ligament tissue. (B) Relationship of hGDF-5, hGDF-6, and hGDF-7 to other members of the BMP/GDF family using the conserved cysteine region of the $\mathrm{COOH}$-terminal polypeptides. The dendogram was generated using the PILEUP program (Genetics Computer Group, Madison, WI). 
Table I. Summary of Histological Analysis of Subcutaneous $G D F$ and BMP Implants at $10 \mathrm{~d}$

\begin{tabular}{lccc}
\hline & $\begin{array}{c}\text { Total No. } \\
\text { implants }\end{array}$ & $\begin{array}{c}\text { Implants with } \\
\text { tendon/ligament }\end{array}$ & $\begin{array}{c}\text { Implants with } \\
\text { bone/cartilage }\end{array}$ \\
\hline Control & 54 & 0 & 0 \\
hGDF-5 & 12 & 12 & 0 \\
hGDF-6 & 18 & 18 & 0 \\
hGDF-7 & 135 & 133 & 0 \\
hBMP-2 & 54 & 0 & 54 \\
\hline
\end{tabular}

The GDFs and/or BMPs to be tested were lyophilized onto DBM particles before implantation at subcutaneous or intramuscular sites, and the ectopic bone formation assay was performed as described by Wang et al. (22).

\section{Production of recombinant GDF proteins}

Recombinant human or mouse GDFs 5, 6, and 7 were expressed in $E$. coli, and were refolded to produce active dimers essentially as de- scribed (23). In brief, the monomeric denatured proteins were isolated from inclusion bodies by acidification and purified oversize exclusion chromatography. The GDFs were refolded into active dimers at $\mathrm{pH} 8.5$ using $2 \% 3$ ([3-cholamidopropryl]-dimethylammonio)-1propanesulfonate, $1.0 \mathrm{M} \mathrm{NaCl}$, and a glutathione redox couple. Final purification was carried out S-Sepharose Fast Flow or HeparinSepharose (Pharmacia LKB Biotechnology Inc., Piscataway, NJ) and reversed-phase HPLC.

\section{Light and electron microscopy}

At death, ectopic or quadriceps implants were removed from each animal and fixed with $4 \%$ paraformaldehyde for light microscopy (LM) or Karnovsky's fixative, and were postfixed in $1 \% \mathrm{OsO}_{4}$ in $0.1 \mathrm{M}$ cacodylate buffer ( $\mathrm{pH}$ 7.4) for electron microscopy (EM; 24). LM samples were embedded in JB4 resin (PolyScience, Warrington, PA) and 5- $\mu \mathrm{m}$ sections were collected and stained with toluidine blue before microscopic observation. EM samples were dehydrated in a graded series of alcohols, and were embedded in Spurr's resin (25). Thin sections $(60 \mathrm{~nm})$ were collected on formvar-coated grids, stained with uranyl acetate and Sato's lead citrate, and viewed (300 transmission electron microscope; Philips, Eindhoven, The Netherlands) at $60 \mathrm{kV}(26)$.
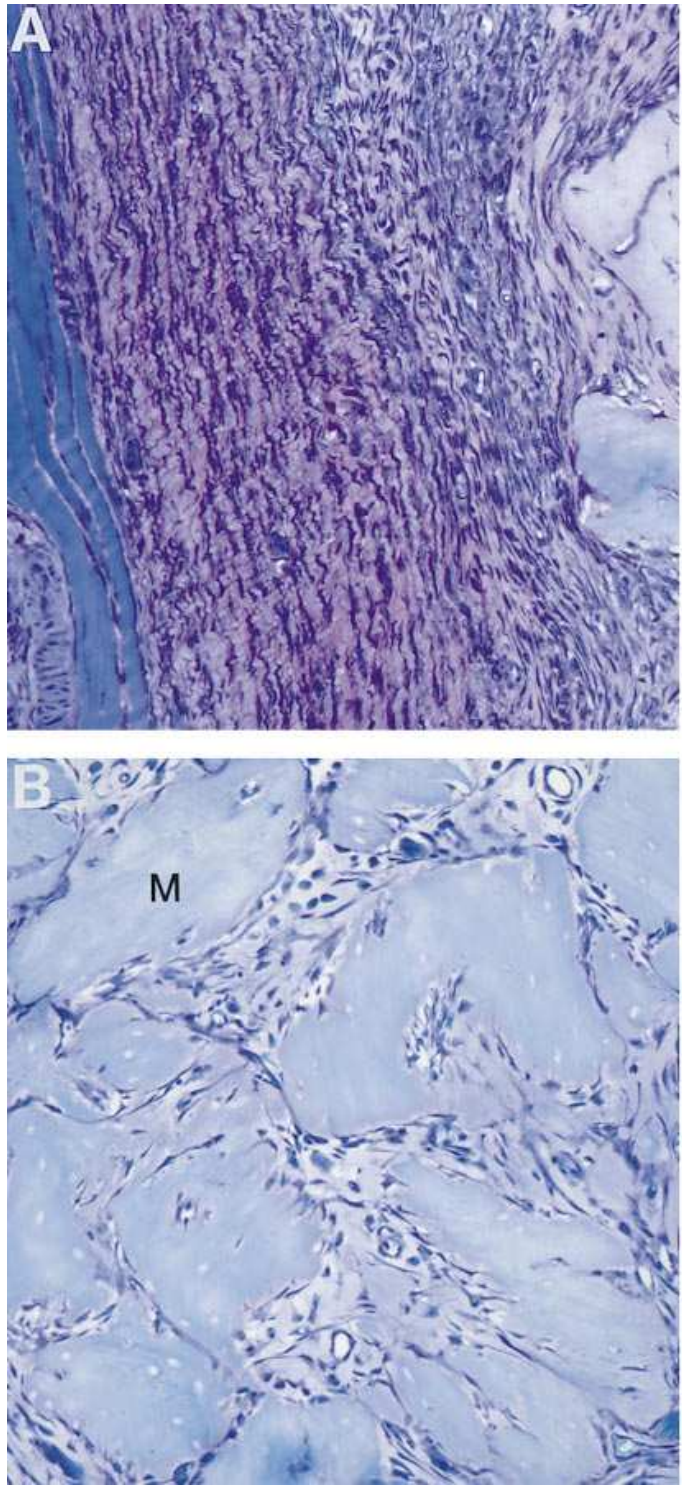
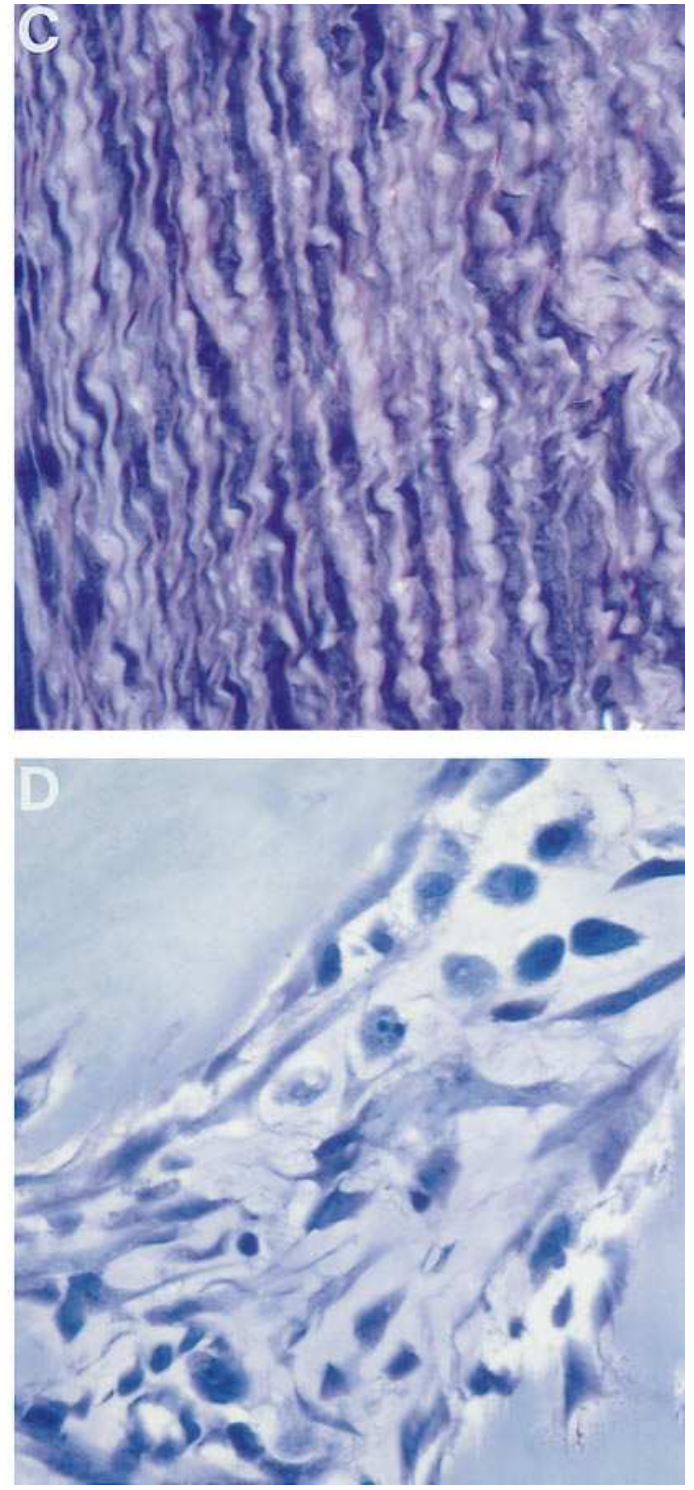

Figure 2. Histology of subcutaneous GDF-7 implants at $10 \mathrm{~d}$. (A) Implant containing $25 \mu \mathrm{g}$ of human GDF-7 shows a highly organized cellular response, with both cells and ECM arranged in a linear manner and displaying a crimped appearance. (B) Control implant showing a typical woundhealing response in which cells and ECM are randomly oriented. ( $M$ denotes DBM carrier). (C) Higher magnification of the GDF-7-induced tissue in $A$. (D) Higher magnification of the control tissue in $B$. 
For measurement of collagen fibers, $10-15$ cross-sectional profiles were measured to reflect the range of fiber diameters present for each tissue shown. Measurements were made using a photomicrographic scale marker (Dunn Scientific, Pacific Palisades, CA).

\section{Northern analysis, $P C R$, and in situ hybridization}

RNA extraction. Total RNA was extracted using guanidine thiocyanate according to the methods described by Sambrook et al. (27).

$R N A$ and DNA probe selection. The mRNAs chosen are known to be expressed in embryonic tendons (Six 1, Six 2; Oliver et al. [7]), adult connective tissues including tendon and ligament (elastin, decorin, and collagen type I); and bone (alkaline phosphatase and osteocalcin).

Northern analysis. $10 \mu \mathrm{g}$ total RNA from each sample was fractionated on denaturing agarose/Mops gels, transferred to nitrocellulose, and hybridized with ${ }^{32} \mathrm{P}$ random primed probes specific for elastin, decorin, alkaline phosphatase, osteocalcin, and Six 1, Six 2.

In situ hybridization studies. 13.5, 14.5, and $15.5 \mathrm{dpc}$ mouse embryos were fixed, embedded in paraffin, and hybridized according to the methods of Lyons et al. (28) to sense and antisense RNA probes

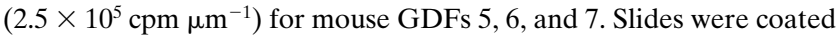
with Ilford $\mathrm{K} 5$ emulsion, developed after $10 \mathrm{~d}$ of exposure time, and stained with toluidine blue before being photographed.
PCR analysis of implants and tendon tissues. RT-PCR was performed using GeneAmp RNA PCR kit (Perkin-Elmer Corp., Norwalk, CT) according to the manufacturer's instructions. In brief, $10 \mathrm{ng}$ of DNase-treated total RNA from the patellar tendons of 6-wk-old rats was reverse transcribed and used for PCR amplification. Oligonucleotide primers were designed based on published sequences for Six 1, Six 2, collagen type I, decorin, and aggrecan. RT-PCR conditions used were $42^{\circ} \mathrm{C}$ for $15 \mathrm{~min}, 99^{\circ} \mathrm{C}$ for $5 \mathrm{~min}$, and $5^{\circ} \mathrm{C}$ for $5 \mathrm{~min}$; then 30 cycles of $95^{\circ} \mathrm{C}$ for $1 \mathrm{~min}, 55^{\circ} \mathrm{C}$ for $1 \mathrm{~min}, 72^{\circ} \mathrm{C}$ for $1 \mathrm{~min}$, followed by $10 \mathrm{~min}$ at $72^{\circ} \mathrm{C}$. PCR products were separated on a $1 \%$ agarose gel containing ethidium bromide, and were visualized under UV illumination.

\section{Results}

LM and EM studies. Ectopic implants have traditionally been useful in the evaluation of the osteogenic potential of BMPs, yet we failed to observe bone formation with implants containing levels of GDFs 5, 6, or 7 20-fold higher than normally needed for bone induction with an osteoinductive protein (21, 22; data not shown). Instead, in 163 of 165 implants performed
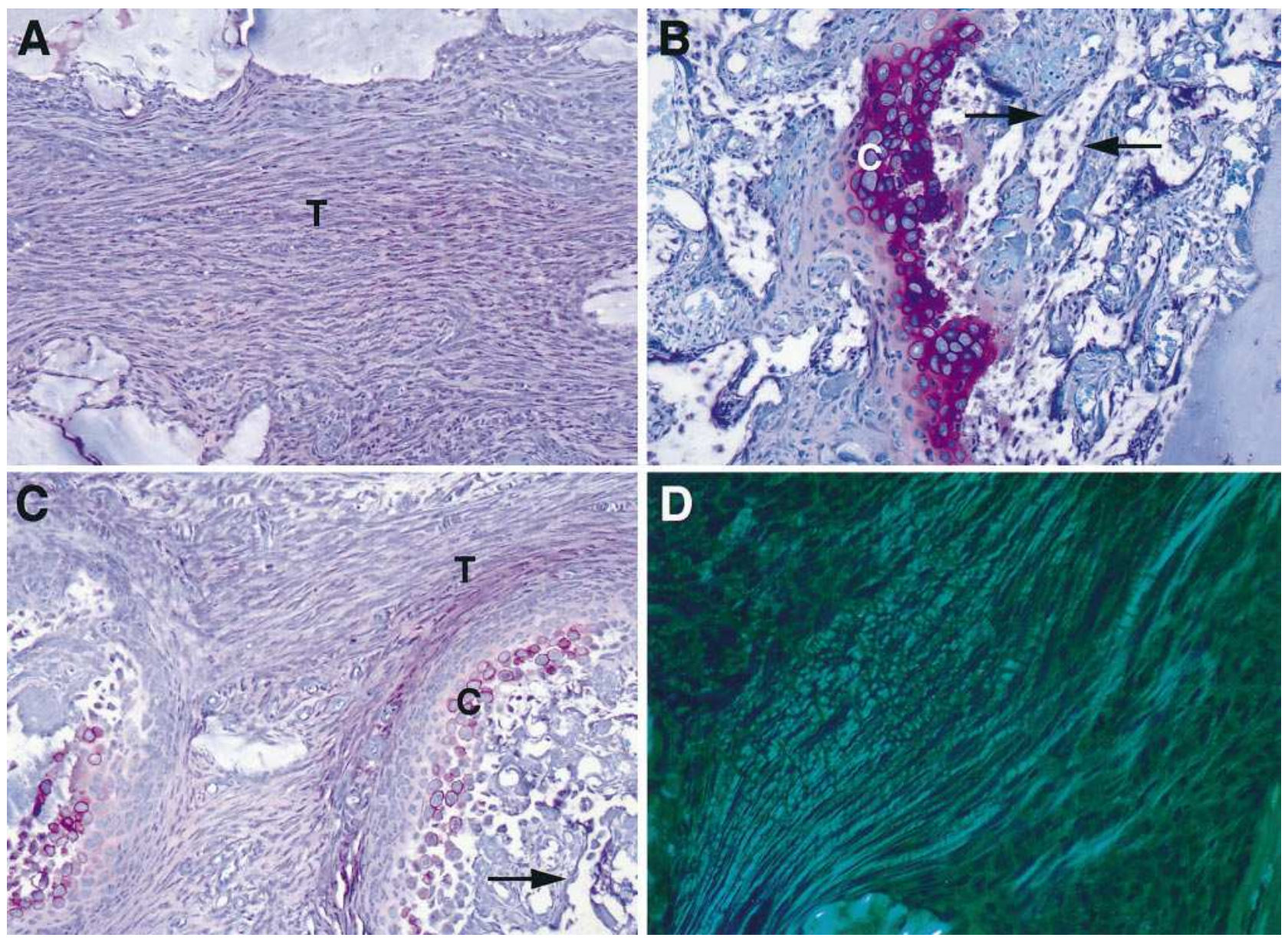

Figure 3. Subcutaneous implantation of GDF-7 $(25 \mu \mathrm{g})$ alone $(A)$ or BMP-2 $(5 \mu \mathrm{g})$ alone $(B)$ or GDF-7 $(25 \mu \mathrm{g})+\mathrm{BMP}-2(5 \mu \mathrm{g}$; $C)$. The tissue formed in response to GDF-7 shows the highly organized linear arrangement of cells before deposition of large amounts of ECM. $(A) \mathrm{T}$ denotes neotendon/ligament tissue. In contrast, the tissue formed in response to implantation of BMP-2 shows large areas of new endochondral bone formation with osteoblasts (bone-forming cells; arrows), chondroblasts (cartilage-forming cells; $C$ ) and abundant bone marrow. When implants contain GDF-7 + BMP-2, both tendon/ligament and bone tissues are present at $10 \mathrm{~d}$ postimplantation. ( $T$, neotendon/ligament; $C$, cartilage; $a r$ row, osteoblasts.) (D) GDF-7 implant (at day 10) viewed with polarizing light. GDF-7-induced tissues have polarizing light patterns like those of tendons and ligaments. 

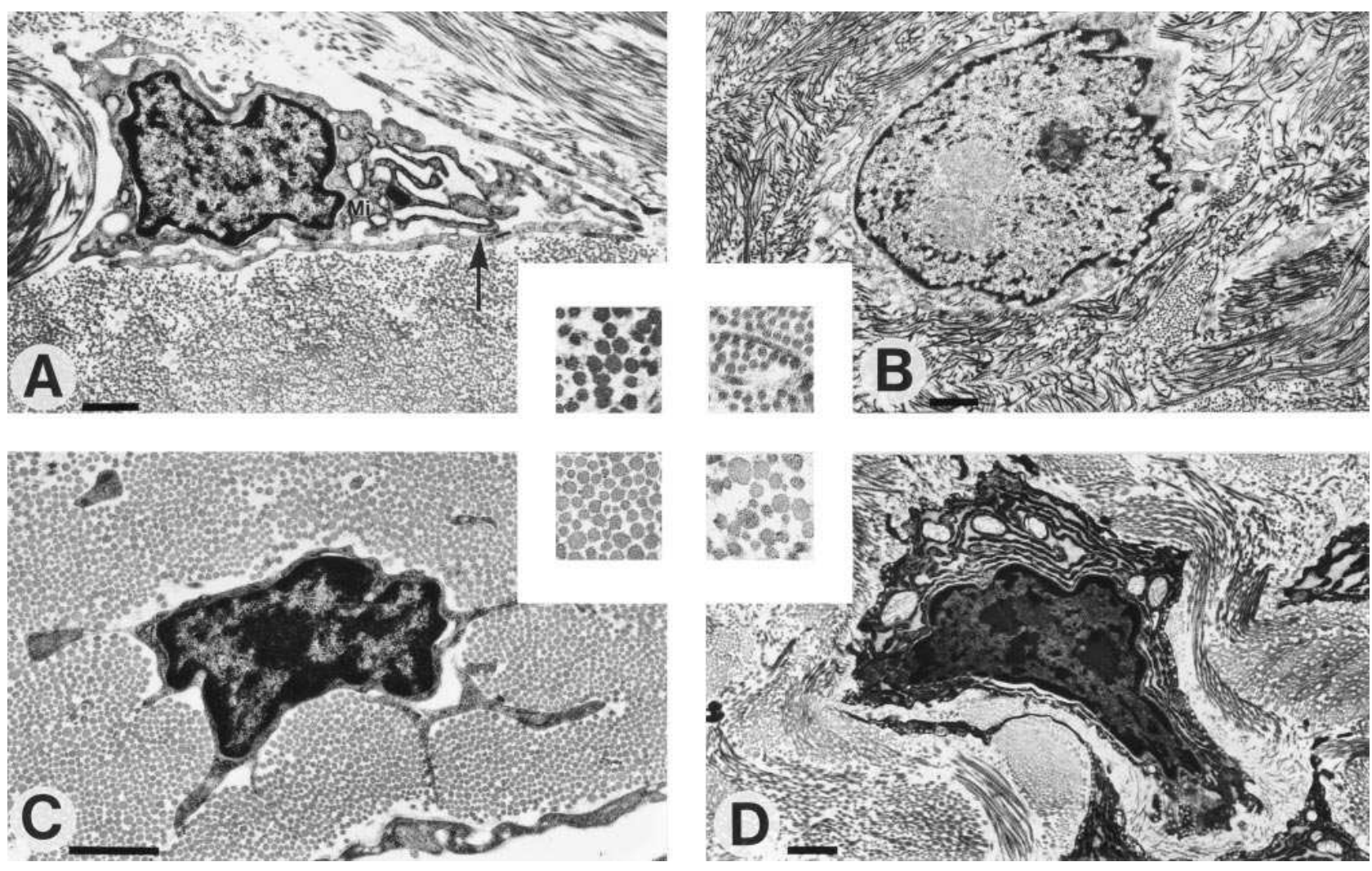

Figure 4. Ultrastructural analysis of the ECM made in response to subcutaneous implantation GDF-7 at 21 d. ( $A$ ) GDF-7 implantation induces the formation of tissue filled with collagen fibrils organized in bundles containing both large and small diameter fibrils (inset, fiber diameters $20 \rightarrow 100 \mathrm{~nm}$ ). Collagen-synthesizing cells are fibroblastic in appearance, with abundant rough endoplasmic reticulum and mitochondria (MI). Cell processes are seen frequently (arrow). (B) Control implants show the maturation of a wound-healing response. The collagen fibrils (inset, fiber diameter $45 \rightarrow 75 \mathrm{~nm}$ ) are organized poorly, and are of fairly uniform size. (C) Tendon from a 2-mo-old rat, taken at the muscle/tendon interface, has characteristic collagen bundles composed of large and small diameter fibrils (inset, fiber diameter $25 \rightarrow 100 \mathrm{~nm}$ ) exhibiting a high degree of organization. $(D)$ Ligament from the same rat. The collagen bundles occur in many orientations, creating a woven or braided morphology. The collagen fibrils are also of varying diameters $(20 \rightarrow 130 \mathrm{~nm})$ as seen in the tendon and GDF-7-induced tissue. On the ultrastructural level, the GDF-7-induced tissues $(A)$ have both tendon and ligament-like characteristics. Magnification bar, $1 \mu \mathrm{m}$. For insets, magnification is $4 \times$ that of $B$ and $D$.

with human GDF-5, GDF-6, or GDF-7, we observed the formation of a connective tissue rich in type I collagen fibers that displayed a wave form and a regular periodicity resembling that of embryonic or neonatal tendon (Table I and Fig. 2). Furthermore, when we coimplanted an osteogenic protein (BMP-2) with human GDF-7, the resulting implants contained both bone and neotendon/ligament-like connective tissue. Discrete areas of each tissue were distributed throughout each implant, suggesting that these molecules have different inductive capabilities (Fig. 3).

We used LM and EM to characterize further the connective tissue induced by these GDFs, and to compare its structure to that of native rat tendon and ligament. While 10-d GDF implants are highly cellular (see Fig. 2), after $21 \mathrm{~d}$ in vivo the implants had undergone remodeling to become largely acellular. Maturing implants consisted of a densely packed connective tissue composed of collagen fibers that under polarizing light showed the intensity of birefringence and the regular periodicity characteristic of tendons and ligaments (Fig. 3). When examined by EM, the GDF-7-induced tissues, like those of tendon and ligament, showed a highly ordered arrangement of collagen bundles (29; Fig. 4). In cross-section, these fascicles were composed of areas of large and small diameter fibrils, a characteristic morphological feature that distinguishes tendon and ligament ECM from the fibril pattern seen in fibrosis that accompanies scar formation (30). For example, collagen bundles made in response to ectopic implantation of GDF-7 are comprised of both large and small diameter fibrils (range of 20-100 nm), in good agreement with bundles found in tendon $(25-100 \mathrm{~nm})$ and ligament $(20-130 \mathrm{~nm})$ of young rats. In contrast, collagen fibrils in control implants are poorly organized, and of fairly uniform size $(45-75 \mathrm{~nm})$ with little resemblance to the pattern seen in dense connective tissue (31).

We then changed the implantation site, and inserted the GDF-containing capsules into the quadriceps muscle of 4-wk-old rats. In 18 out of 18 implants, GDFs produced larger amounts of neotendon/ligament-like tissue than that seen when an equal amount of protein was implanted at the subcutaneous site. In contrast, BMP-2 implants resulted in only endochondral bone formation (data not shown). Upon ultrastructural analysis, the GDF-7 implants contained the same fibril morphology as we observed at the subcutaneous site. Frequently elastin was dispersed among the fibrils (Fig. 5), a feature of in situ tendon and ligament tissue. The cells in this dense connec- 

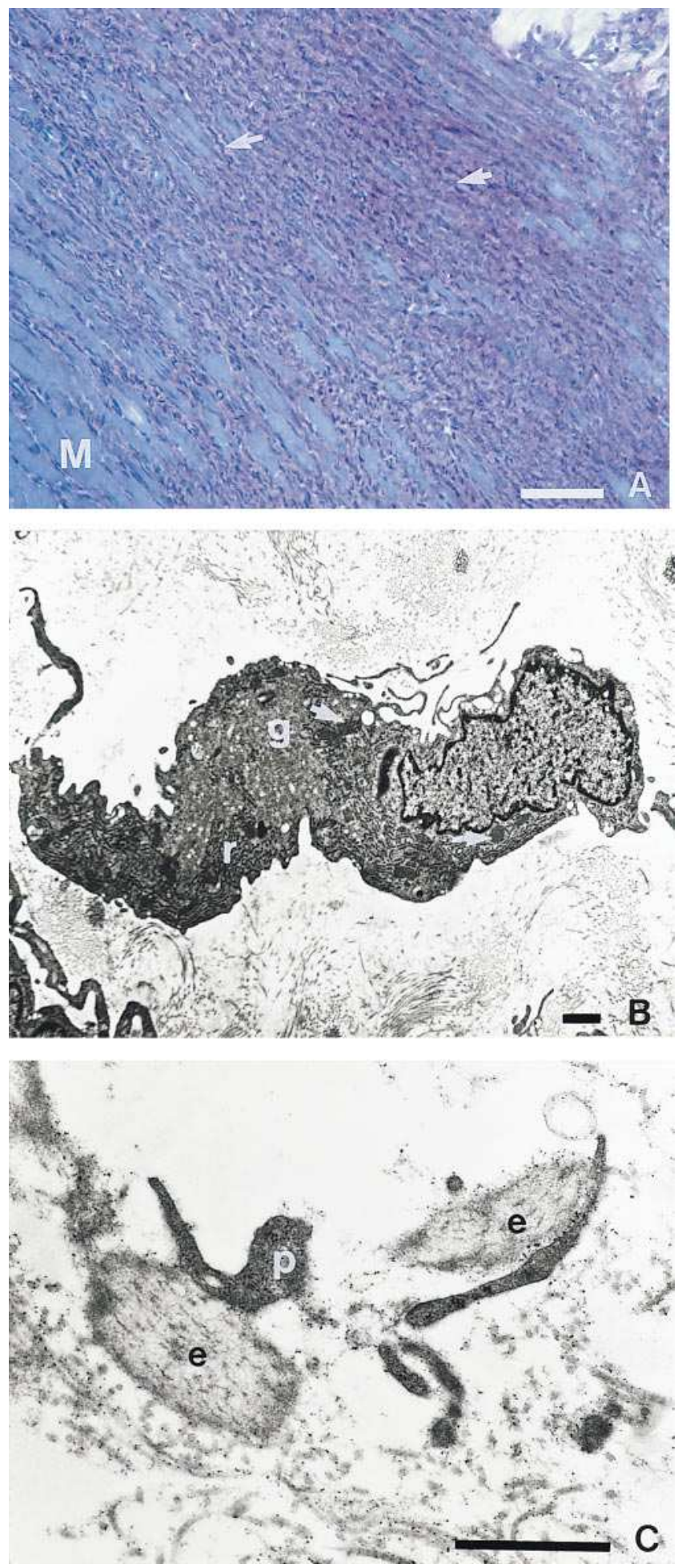

Figure 5. Implantation of GDF-7 for $10 \mathrm{~d}$ at a muscle site induces neotendon/ligament-like tissue. $(A)$ Light micrograph of cells at the GDF-7 implantation site. The cells have a crimped appearance (arrows) and are surrounded by a proteoglycan-rich matrix (pink). $M$, muscle. $(B)$ Electron micrograph of these cells showing an extensive Golgi complex $(g)$, rough endoplasmic reticulum $(r)$, and numerous mitochondria (arrows). (C) Ultrastructural analysis of the collagenous matrix induced by GDF-7 reveals areas containing elastin $(e)$ closely apposed to cell processes $(p)$. Scale marks $=100 \mu \mathrm{m}$ in $A$ and $1 \mu \mathrm{m}$ in $B$ and $C$.
Table II. Expression of Connective Tissue Markers in Ectopic Tissues Induced by GDF-7 and BMP-2

\begin{tabular}{|c|c|c|c|c|c|c|}
\hline \multirow[b]{2}{*}{ Marker } & \multirow{2}{*}{$\begin{array}{c}\mathrm{T} / \mathrm{L} \\
\text { embryonic }\end{array}$} & \multirow{2}{*}{$\begin{array}{l}\mathrm{T} / \mathrm{L} \\
\mathrm{Ad}\end{array}$} & \multicolumn{2}{|c|}{ GDF-7 } & \multirow{2}{*}{$\begin{array}{c}\text { BMP-2 } 2 \\
10 \mathrm{~d}\end{array}$} & \multirow{2}{*}{$\begin{array}{l}\text { Contro } \\
10 \mathrm{~d}\end{array}$} \\
\hline & & & $3 \mathrm{~d}$ & $10 \mathrm{~d}$ & & \\
\hline Six $1 / \operatorname{Six} 2$ & $+^{7}$ & + & \pm & \pm & - & - \\
\hline Elastin & $+{ }^{32}$ & $+^{3}$ & + & + & - & - \\
\hline Decorin & $+{ }^{33}$ & + & + & + & + & + \\
\hline Collagen I & $+{ }^{32,33}$ & + & + & + & + & + \\
\hline Aggrecan & $\pm^{33}$ & + & - & \pm & - & - \\
\hline Alphos & $-*$ & - & - & - & + & - \\
\hline $\mathrm{OCN}$ & -31 & - & - & - & + & - \\
\hline
\end{tabular}

The level of expression of mRNAs found in developing tendons (Six 1 and Six 2), adult connective tissues including tendon and ligament (elastin, decorin, and collagen I), cartilage (aggrecan), and bone (Alphos, alkaline phosphatase; $O C N$, osteocalcin) are compared in GDF-7 and BMP-2-induced tissues. $T / L$, embryonic tendon/ligament; $A d$, adult tendon/ligament; $3 \mathrm{~d}, 3 \mathrm{~d}$ postimplantation; $10 \mathrm{~d}, 10 \mathrm{~d}$ postimplantation; Control, tissue induced in response to implantation of the carrier matrix used to deliver GDF-7 and BMP-2. +, strong signal; \pm , weak signal; -, no signal. References for published expression data are denoted by superscript numbers. *Hattersley, G., unpublished observations.

tive tissue matrix were highly synthetic in nature, containing large amounts of rough endoplasmic reticulum, many mitochondria, and a well-developed Golgi complex. The overall morphology of these cells was similar to that observed with tenocytes and ligament fibroblasts.

Northern analysis and PCR. To characterize further the GDF-induced tissues on a molecular level, we assembled a battery of probes for genes expressed in developing musculoskeletal tissues, including the newly identified tendonexpressed homeobox-containing genes Six 1 and Six 2. We performed Northern and PCR analysis on total and poly $(\mathrm{A})^{+}$ RNA collected from GDF-7-induced subcutaneous implants, and compared this marker profile to control implants, to implants induced by BMP-2, and to the gene expression pattern seen in embryonic and adult tendons and ligaments. In addition, we examined the implants for the presence of mRNAs for matrix proteins known to be expressed in mature tendon, ligament, bone, and cartilage. These included aggrecan (which is highly expressed in cartilage and is found in tendon/ligament at low levels) elastin, decorin, and collagen type I (which are present in tendon and ligament), and alkaline phosphatase and osteocalcin, proteins that are abundant in bone $(21,32)$. A compilation of these data is shown in Table II and Fig. 6.

RNAs collected from GDF implants had few similarities with those containing bone induced by BMP-2. Most notably, we found no evidence of osteocalcin, a matrix protein thought to be exclusive to bone and hypertrophic cartilage, or alkaline phosphatase, an enzyme made by bone cells. Some overlap in expression was observed with the cartilage marker aggrecan. Aggrecan mRNA was present in GDF-5, -6, or 7-induced tissue, a finding consistent with the ability of cells resident in tendons and ligaments to produce a fibrocartilaginous ECM when placed under physiological stress (33-36); and was also found in BMP-2-induced tissues during the cartilage phase of endochondral bone formation. Matrix proteins known to be abundant in adult tendon/ligament were present in the GDF im- 


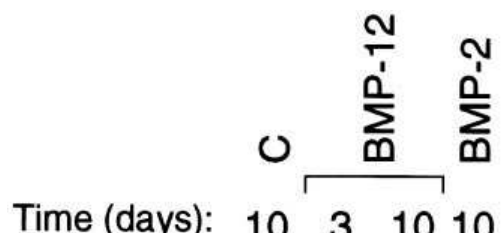

Time (days): $10 \quad 3 \quad 1010$

a
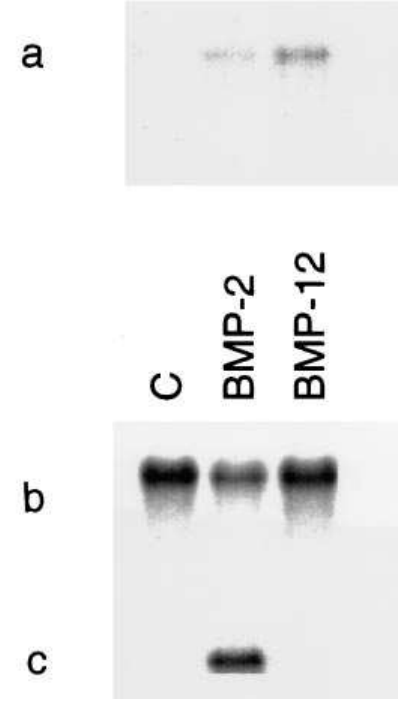

Figure 6. Northern analysis of tissues induced by ectopic implantation of BMP-2 (5 $\mu \mathrm{g})$, GDF-7 $(25 \mu \mathrm{g})$, or control, and probed with cDNAs for $(a)$ elastin, $(b)$ decorin, or (c) alkaline phosphatase.

plants with elastin, collagen type I, and decorin showing high levels of expression. Except for elastin, these RNAs were also present in BMP-2 and control implants, reflecting the abundance of structural proteins in all types of connective tissues. Some of the mRNAs reported to be present in embryonic tendon were expressed in the GDF-7 implants. These included the matrix proteins aggrecan, collagen type II (data not shown), collagen type I, decorin, elastin, and the homeoboxcontaining genes Six 1 and Six 2. When we examined mature tendons for the presence of tendon-associated markers using PCR analysis, we also found the expression of collagen type I, decorin, aggrecan, Six 1, and Six 2, similar to the pattern of matrix proteins expressed in GDF-7 implants.

Localization of GDFs 5, 6, and 7 in developing joints. We used in situ hybridization techniques to determine if GDF-5, -6, or -7 transcripts were present in areas consistent with their involvement in embryonic tendon and ligament formation. As shown in Fig. 7, GDFs 5, 6, and 7 have distinct patterns of expression during connective tissue morphogenesis. At $13.5 \mathrm{dpc}$, GDF-5 is expressed at the interface between mesenchymal condensations in the developing limbs. This expression domain corresponds to the region that will ultimately form synovial joints between skeletal elements. By 15.5 dpc, expression of GDF-5 has become restricted to the periarticular surface of the joint, and is most likely expressed by developing articular chondrocytes. Expression at this stage is also seen in a small region of the perichondrium adjacent to the zone of chondrocyte proliferation. GDF-5 transcripts are not only detected within the appendicular skeleton, but also between mesenchymal condensations within the axial skeleton that constitute the vertebral column (data not shown). GDF-6 transcripts show a more restricted pattern of expression to that of GDF-5. Unlike GDF-5, which is expressed in all joints within the limbs, GDF-6 is expressed only in the carpal/metacarpal and tarsal/ metatarsal joints. No detectable coexpression of GDF-7 with either GDF-5 or GDF-6 has been observed. Instead, GDF-7 hybridization is seen in the region of the developing shoulder (see Fig. 7). GDF-7 is also expressed at the most distal tips of the digits, adjacent to the forming tendons at this site.

\section{Discussion}

When compared to our current understanding of the cell types and signaling molecules required for skeletal morphogenesis, little is known about the regulatory factors important for tendon and ligament formation. GDFs 5, 6, and 7, three members of the TGF- $\beta$ gene superfamily, are able to induce formation of a dense connective tissue when implanted ectopically or intramuscularly in rats. By all existing criteria available for comparison, histological and morphological analysis of the tissue, and Northern analysis and PCR of the mRNAs induced, the characteristics of the GDF-induced tissue are the same as those seen in tendon and ligament $(5,7,8,15,29,33,34)$. These data suggest that progenitor cells capable of synthesizing dense connective tissue are present in adult animals at both subcutaneous and intramuscular sites, and that these cells can be influenced to differentiate in the presence of an appropriate stimulus, GDF-5, -6, or -7, along a tendon/ligament pathway.

Our results highlight the complex lineage relationship that exists between skeletal progenitor cells and their connective tissue counterparts. During embryogenesis, tendons and ligaments appear to convert to fibrocartilage at their sites of attachment to bones (4). This ability to alter their phenotype remains in adults, where central areas of tendon/ligament begin to produce cartilage matrix proteins when subjected to high load or stress as they pass over bony surfaces, perhaps reflecting the common ancestry of connective tissue progenitors and cartilage-forming cells $(5,6,35,36)$.

Abnormal tendon patterning has been shown to occur in mouse limbs when skeletal patterning is disrupted through loss of Wnt-7a, and in chick limbs when the apical ectodermal ridge is removed prematurely (37-39). This is also the case in $b p / b p$ mice in which the loss of GDF-5 results in deformed or missing skeletal and connective tissue structures at the same anatomical locations (40). The connective tissue defects seen in all of these animals may be secondary events, linked to skeletal malformations. Alternatively, the skeletal and connective tissue abnormalities observed in these systems may be independent developmental events affected by common regulatory signals. The current lack of phenotypic markers for connective tissue precursor cells makes it difficult to distinguish experimentally between these possibilities. It is likely that both tendon/ligament and cartilage precursor cells are found within early condensations, and are influenced by similar or related signaling molecules during the morphogenetic events that determine limb formation. The absence of these signals after adult tendon/ligament injury may preclude functional healing of these tissues, and be responsible for the scar tissue that forms instead.

Our studies add further support to the central role that members of the TGF- $\beta$ gene superfamily play during morphogenesis and tissue formation (21). We suggest, based on our in vivo experiments and the localization of GDF transcripts during mouse development $(19,20)$, that one function of GDFs 5 , 6 , and 7 is to influence the differentiation of connective tissue precursors into tendon/ligament-forming cells. As is the case for the osteogenic BMPs, where roles in embryonic skeletal 

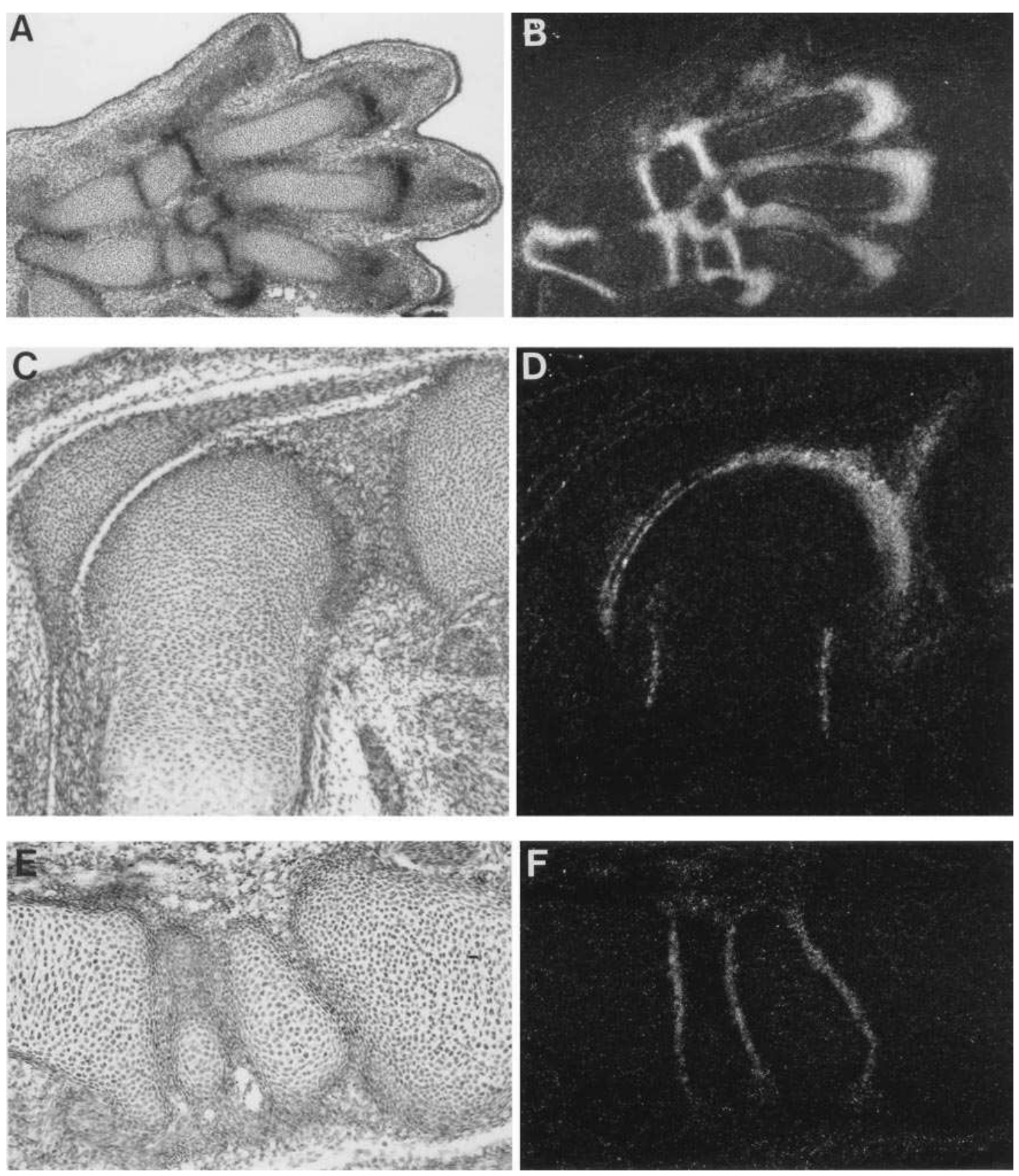

Figure 7. In situ localization of GDF-5, -6, and -7 transcripts in the developing mouse embryo. ( $A$ and $B$ ) GDF-5 expression at 13.5 dpc is seen in the interface between mesenchymal condensations in developing synovial joints. ( $C$ and $D$ ) GDF-5 expression at 15.5 dpc in the periarticular surface of the knee joint, and in the perichondrium of the femur adjacent to zone of chondrocyte proliferation. (E-H) GDF-6 expression in the wrist $(E$ and $F)$ and the ankle $(G$ and $H$ ) joints at 15.5 dpc. ( $I$ and $J$ ) GDF-7 mRNA localizes to the insertion site of the developing tendon/ligament and not to the cartilage or osteogenic areas of the scapula. ( $K$ and $L$ ) GDF-7 expression in the distal tips of digits adjacent to tendons in the 14.5 dpc mouse embryo.

formation translate into an ability to repair adult bone, GDFs 5,6 , and 7 may prove to be useful in the repair and regeneration of tendon/ligament injuries in adults. Evaluation of in vivo experiments aimed at testing the ability of GDFs to repair adult tendons and ligaments is currently underway.

\section{Acknowledgments}

We thank G. Oliver for providing probes for Six 1 and Six 2, C. Tickle for her ideas on embryonic tendon-specific markers, K. Lyons, D.
Kingsley, S. Thies, and S. Clark for their helpful comments on this manuscript, D. Melton and G. Thomsen for their contribution in designing the degenerate oligonucleotides used in the genomic PCR experiments, L. Haines for performing the DNA sequencing, and R. Hewick and J. McCoy for their support and interest in this work.

\section{References}

1. Daniel, R.K., and W.C. Breidenbach. 1982. Tendon: structure, organization, and healing. In The Musculoskeletal System. Embryology, Biochemistry, and Physiology. R.L. Cruess, editor. Churchill Livingston, New York. 383-399. 

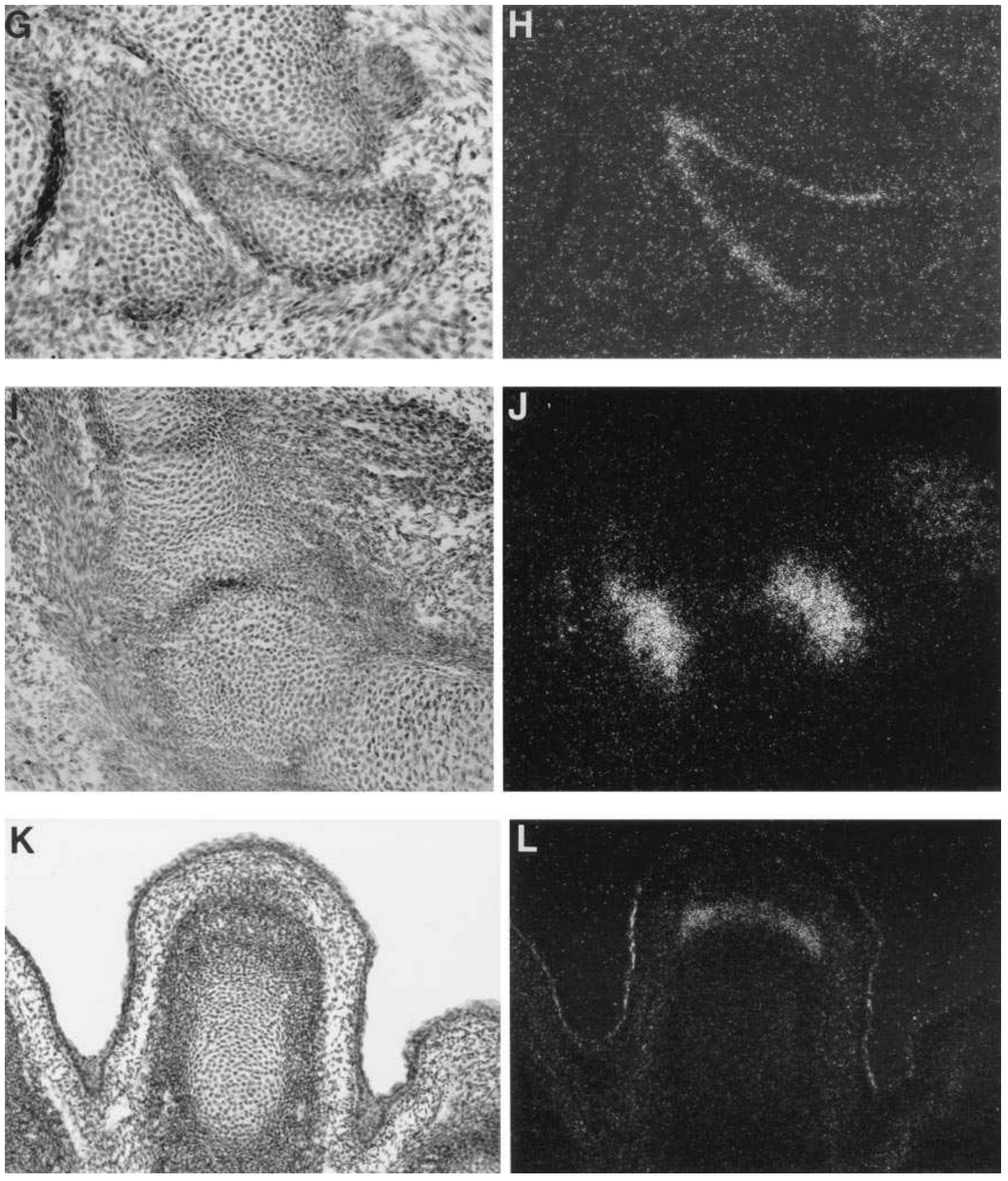

Figure 7 (Continued)

2. Byers, P.D. 1994. Histological features of connective tissues. In Diseases of Bones and Joints: Cell Biology, Mechanism and Pathology. J.R. Salisbury, C.G. Woods, and P.D. Byers, editors. Chapman and Hall Medical, London. 476-508

3. Amiel, D., E. Billings, Jr., and W.H. Akeson. 1990. Ligament structure, chemistry, and physiology. In Knee Ligaments: Structure, Function, Injury and Repair. D. Daniel, W.H. Akeson, and J. O'Connor, editors. Raven Press Ltd., New York. 77-94.

4. Hurle, J.M., M.A. Ros, Y. Ganan, D. Macias, M. Critchlow, and J.R. Hinchliffe. 1990. Experimental analysis of the role of ECM in the patterning of the distal tendons of the developing limb bud. Cell Differ. Dev. 30:97-108.

5. Matyas, J.R., M.G. Anton, N.G. Shrive, and C.B. Frank. 1995. Stress governs tissue phenotype at the femoral insertion of the rabbit MCL. J. Biomech. 28:147-157.

6. Ralphs, J.R., R.N.S. Tyers, and M. Benjamin. 1992. Development of functionally distinct fibrocartilages at two sites in the quadriceps tendon of the rat: the suprapatella and the attachment to the patella. Anat. Embryol. 185:181187.
7. Oliver, G., R. Wehr, N.A. Jenkins, N.G. Copeland, B.N.R. Cheyette, V. Hartenstein, S.L. Zipursky, and P. Gruss. 1995. Homeobox genes and connective tissue patterning. Development. 121:693-705.

8. Ginsburg, G.T., D. Royster, G. Kassabian, G.F. Shuler, W.R. Dougherty, and A.C. Sank. 1995. Mesenchymal commitment to digital joint formation. Ann Plast. Surg. 35:95-104.

9. Favier, B., F.M. Rijli, C. Fromental-Ramain, V. Fraulob, P. Chambon, and P. Dolle. 1996. Functional cooperation between the non-paralogous genes Hoxa-10 and Hoxd-11 in the developing forelimb and axial skeleton. Development. 122:449-460.

10. Schmidt, C.C., H.I. Georgescu, C.K. Kwoh, G.L. Blomstrom, C.P. Engle, L.A. Larkin, C.H. Evans, and S.L.-Y. Woo. 1995. Effect of growth factors on the proliferation of fibroblasts from the medial collateral and anterior cruciate ligaments. J. Orthop. Res. 13:184-190.

11. Conti, N.A., and L.E. Dahners. 1993. The effect of exogenous growth factors on ligament healing. Trans. Orthop. Res. Soc. 18:60.

12. Letson, A.K., and L.E. Dahners. 1994. The effect of combinations of growth factors on ligament healing. Clin. Orthop. Relat. Res. 308:207-212. 
13. Caubaud, J.E., W.G. Rodkey, and J.A. Feagin. 1979. Experimental studies of acute anterior cruciate ligament injury and repair. Am. J. Sports Med. 7: $18-22$

14. Amiel, D., J.B. Kleiner, and W.H. Akeson. 1986. The natural history of the anterior cruciate ligament autograft of patellar tendon origin. Am. J. Sports Med. 14:449-462.

15. Amiel, D., S. Kulper, and W.H. Akeson. 1990. Cruciate ligaments. Response to injury. In Knee Ligaments: Structure, Function, Injury and Repair. D. Daniel, W.H. Akeson, and J. O'Connor, editors. Raven Press Ltd., New York. 365-377.

16. Nakamura, N., S. Horibe, N. Matsumoto, T. Tomita, T. Natsuume, Y. Kaneda, K. Shino, and T. Ochi. 1996. Transient introduction of a foreign gene into healing rat patellar ligament. J. Clin. Invest. 97:226-231.

17. Hotten, G., H. Neidhardt, B. Jacobwsky, and J. Pohl. 1994. Cloning and expression of recombinant human growth/differentiation factor 5. Biochem. Biophys. Res. Commum. 204:646-652.

18. Wolfman, N.M., A.J. Celeste, K. Cox, G. Hattersley, R. Nelson, N. Yamaji, E. DiBlasio-Smith, J. Nove, J.J. Song, J.M. Wozney, and V. Rosen. 1995. Preliminary characterization of the biological activities of rhBMP-12. J. Bone Miner. Res. 10:s148.

19. Storm, E.E., T.V. Huynh, N.G. Copeland, N.A. Jenkins, D.M. Kingsley, and S.-J. Lee. 1994. Limb alterations in brachypodism mice due to mutations in a new member of the TGF- $\beta$ superfamily. Nature (Lond.). 368:639-642.

20. Chang, S.C., B. Hoang, J.T. Thomas, S. Vukicevic, F.P. Luyten, N.J.P. Ryba, C.A. Kozak, A.H. Reddi, and M. Moos, Jr. 1994. Cartilage-derived morphogenetic proteins. J. Biol. Chem. 269:28227-28234.

21. Rosen, V., and R.S. Thies. 1992. The BMP proteins in bone formation and repair. Trends Genet. 8:97-102.

22. Wang, E.A., V. Rosen, P. Cordes, R.M. Hewick, M.J. Kriz, D.P. Luxenberg, B.S. Sibley, and J.M. Wozney. 1988. Purification and characterization of other distinct bone-inducing factors. Proc. Natl. Acad. Sci. USA. 85:9484-9488.

23. Schlunegger, M.P., Cerletti, N., Cox, D.A., McMaster, G.K., Schmitz, A., and Grutter, M.G. 1992. Crystallization and preliminary X-ray analysis of recombinant human transforming growth factor B2. FEBS (Fed. Eur. Biochem. Soc.) Lett. 303:91-93.

24. Karnovsky, M.J. 1965. A formaldehyde-glutaraldehyde fixative of high osmolarity for use in electron microscopy. J. Cell Biol. 27:137a.

25. Spurr, A.R. 1969. A low-viscosity epoxy resin embedding medium for electron microscopy. J. Ultrastruct. Res. 26:31-43.

26. Sato, J. 1968. A modified method for lead staining of thin sections. $J$.
Electron. Microsc. (Tokyo). 17:158-159.

27. Sambrook, J., E.F. Fritsch, and T. Maniatis. 1989. Molecular Cloning: A Laboratory Manual. Cold Spring Harbor Laboratory, Cold Spring Harbor, NY. 28. Lyons, K.M., R.W. Pelton, and B.M.L. Hogan. 1990. Organogenesis and pattern formation in the mouse: RNA distribution patterns suggest a role for bone morphogenetic protein-2A (BMP-2A). Development. 190:833-844.

29. Christel, P.S., and D.F. Gibbons. 1993. Collagen fiber changes in the exercised, immobilized, or injured anterior cruciate ligament. In The Anterior Cruciate Ligament: Current and Future Concepts. D.W. Jackson, editor. Raven Press Ltd., New York. 195-209.

30. Grotendorst, G.R., and G.R. Martin. 1986. Cell movements in woundhealing and fibrosis. Rheumatology. 10:385-403.

31. Arnoczky, S.P., J.R. Matyas, J.A. Buckwalter, and D. Amiel. 1993. Anatomy of the anterior cruciate ligament. In The Anterior Cruciate Ligament: Current and Future Concepts. D.W. Jackson, editor. Raven Press Ltd., New York. 5-22.

32. Lian, J.B., and C.M. Gundberg. 1988. Osteocalcin. Clin. Orthop. Rel. Res. 226:267-291.

33. Hurle, J.M., G. Corson, K. Daniels, R.S. Rieter, L.Y. Sakai, and M.S Solursh. 1994. Elastin exhibits a distinctive temporal and spatial pattern of distribution in the developing chick limb in association with the establishment of the cartilaginous skeleton. J. Cell. Sci. 107:2623-2634.

34. Robbins, J.R., and K.G. Vogel. 1994. Regional expression of mRNA for proteoglycans and collagen in tendon. Eur. J. Cell. Biol. 64:264-270.

35. Vogel, K.G., J.D. Sandy, G. Pogany, and J.R. Robbins. 1994. Aggrecan in bovine tendon. Matrix Biol. 14:171-179.

36. Vogel, K.G., A. Ordog, G. Pogany, and J. Olah. 1993. Proteoglycans in the compressed region of human tibialis posterior tendon and in ligaments. $J$. Orthop. Res. 11:68-77.

37. Parr, B.A., and A.P. McMahon. 1995. Dorsalizing signal Wnt-7a required for normal polarity of D-V and A-P axes of mouse limb. Nature (Lond.). 374:350-353.

38. Kieny, M., and A. Chevallier. 1979. Autonomy of tendon development in the embryonic chick wing. J. Embryol. Exp. Morphol. 49:153-165.

39. Hurle, J.M., and Y. Ganan. 1986. Interdigital tissue chondrogenesis induced by surgical removal of the ectoderm in the embryonic chick leg bud. $J$. Embryol. Exp. Morphol. 94:231-244.

40. Grunenberg, H., and A.J. Lee. 1973. The anatomy and development of brachypodism in the mouse. J. Embryol. Exp. Morphol. 30:119-141. 